\title{
Discrepância entre disposição a pagar e a receber pelas plantas úteis em comunidades tradicionais
}

Com o surgimento de ameaças ambientais, as áreas litorâneas na Amazônia podem ter seu fluxo de serviços ecossistêmicos comprometidos, sobretudo o de provisão, em locais onde as populações tradicionais estão estabelecidas há décadas. Neste sentido, a Reserva Extrativista Marinha de Soure, localizada em área costeira no arquipélago do Marajó, vem sofrendo com práticas que ameaçam os recursos ecossistêmicos, que futuramente podem desaparecer se tais práticas não forem combatidas. As comunidades pertencentes à Reserva Extrativista de Soure (Vila de Pesqueiro, Povoado do Caju-Úna e Comunidade do Céu) caracterizamse pelo seu modo de vida tradicional, as quais desenvolveram práticas que denotam forte relação de dependência com os recursos da natureza, como por exemplo a pesca, a extração de frutos e sementes e o uso da medicina tradicional. Dentro desse contexto, este trabalho teve como objetivo valorar economicamente as plantas úteis nestas comunidades, para tal foi adotado o Método de Valoração de Contingente, usando-se as técnicas de Disposição a Pagar e Disposição a Receber O valor estimado pela Disposição a Receber foi de R\$ 3.628.208,88/ano e o da Disposição a Pagar foi R\$ 519.613,20/ano, os quais podem ser usados como subsídio para a criação de projetos que garantam e reforcem a conservação das plantas úteis.

\section{Discrepancy between willingness to pay and receive for useful plants in traditional communities}

\begin{abstract}
With the emergence of environmental threats, coastal areas in the Amazon may have their flow of ecosystem services compromised, especially provision, in places where traditional populations have been established for decades. In this sense, the Soure Marine Extractive Reserve, located in a coastal area in the Marajó archipelago, has been suffering from practices that threaten ecosystem resources, which in the future may disappear if such practices are not combated. The communities belonging to the Soure Extractive Reserve (Vila de Pesqueiro, Povoado do Caju-Úna and Comunidade do Céu) are characterized by their traditional way of life, which have developed practices that show a strong relationship of dependence with the resources of nature, such as for example fishing, the extraction of fruits and seeds and the use of traditional medicine. Within this context, this paper aimed to economically value useful plants in these communities, for this purpose the Contingent Valuation Method was adopted, using the Willingness to Pay and Willingness to Receive techniques. The amount estimated by the Willingness to Accept was R\$3.628.208,88/year and the Willingness to Pay was R\$ 519.613,20/year, which can be used as a subsidy for the creation of projects that guarantee and reinforce the conservation of useful plants.
\end{abstract}

Keywords: Contingent valuation; Amazon; Marajó Archipelago; Resex-Mar de Soure.

Topic: Valoração e Economia Ambiental

Reviewed anonymously in the process of blind peer.
Received: 06/10/2020

Approved: $28 / 11 / 2020$
Davison Márcio Silva de Assis (iD)

Universidade Federal do Pará, Brasil

http://lattes.cnpq.br/3107290671697620

http://orcid.org/0000-0002-6693-5883

davison-assis@hotmail.com

Ana Cláudia Caldeira Tavares Martins

Universidade do Estado do Pará, Brasil

http://lattes.cnpq.br/6547250062275801

http://orcid.org/0000-0003-4972-036X

tavaresmartins7@gmail.com

Norma Ely Santos Beltrão (iD

Universidade do Estado do Pará, Brasil

http://lattes.cnpq.br/9434131723316393

http://orcid.org/0000-0003-1991-2977

normaelybeltrao@gmail.com
Priscila Sanjuan de Medeiros Sarmento

Instituto Tecnológico Vale Desenvolvimento Sustentável, Brasil

http://lattes.cnpq.br/5138782013605157

http://orcid.org/0000-0002-5001-9573

priscilasanjuanbio@yahoo.com.br
Referencing this:

ASSIS, D. M. S.; MARTINS, A. C. C. T.; BELTRAO, N. E. S.; SARMENTO, P. S. M.. Discrepância entre disposição a pagar e a receber pelas plantas úteis em comunidades tradicionais. Revista Ibero Americana de Ciências Ambientais, v.11, n.6, p.725-737, 2020. DOI: http://doi.org/10.6008/CBPC2179-6858.2020.006.0058 


\section{INTRODUÇÃO}

O capital natural, compreendido como o estoque de recursos naturais, fornece um fluxo de serviços tangíveis e intangíveis, direta e indiretamente úteis, os quais são fundamentais para proporcionar qualidade de vida e satisfazer o bem-estar humano (DALY, 2020; SMITH et al., 2017). Os benefícios que podem ser desfrutados por meio do uso do capital natural, são traduzidos em Serviços Ecossistêmicos (SE's), e estes por sua vez se dão em função da capacidade que os processos naturais possuem de prove-los (KVALVIK et al., 2020).

Apesar das sociedades humanas usufruírem dos benefícios proporcionados pela natureza, a degradação ambiental e consequentemente a perda da biodiversidade comprometem o fluxo futuro dos SE's (BRANDER et al., 2012; CRESPIN et al., 2016). Diante desse quadro de degradação, o governo brasileiro no ano de 1937 promove a I Conferencia para Proteção da Natureza, que culminou na criação do primeiro Parque Nacional, o Parque do Itatiaia, cujo objetivo era servir de campo para pesquisas científicas, assim como para o lazer das populações urbanas (SILVA, 2015).

A partir deste grande marco, no ano de 1988, a Organização não Governamental (ONG) Fundação Pró-Natureza (Funatura) foi solicitada para formular um sistema nacional para conservação da biodiversidade, entretanto foi somente no ano de 2000, por meio da lei 9.985/2000 que o Sistema Nacional de Unidades de Conservação - SNUC foi oficialmente instituído (SILVA, 2015). Dentro desse contexto, a criação das Unidades de Conservação (UC's) tornam-se o principal instrumento, no Brasil, para assegurar a proteção de áreas de importância biológica e cultural, ou mesmo garantir o seu uso sustentável pelas populações tradicionais (TEIXEIRA et al., 2017).

Embora as Unidade de Conservação, constituam-se como um instrumento para proteção dos recursos naturais, a Reserva Extrativista Marinha de Soure (Resex-Mar Soure), criada para proteger a fauna e a flora local (OLIVEIRA JUNIOR et al., 2012), pode ter seu fluxo futuro de SE's comprometido devido as ameaças à sua biodiversidade, conforme relatado por Lobato et al. (2014). As comunidades que compõem a Resex-Mar Soure apresentam uma estreita relação com a natureza, e isso é notável através do uso dos recursos naturais que caracterizam seu modo de vida tradicional. Dentre as atividades que evidenciam essa relação as principais são a pesca, o artesanato e o extrativismo vegetal (OLIVEIRA JUNIOR et al., 2012; CARDOSO, 2014).

No que diz respeito ao uso de espécies vegetais, o estudo de Rocha et al. (2017) revelou a existência de uma forte relação de dependência dos comunitários com esses recursos, através do uso de nove categorias de plantas úteis, o que acabou por demonstrar, indiretamente, que estes fornecem serviço ecossistêmico de provisão.

Embora os serviços prestados pelos ecossistemas sejam extremamente importantes para o bemestar humano, eles permanecem subvalorizados pela sociedade (GROOT et al., 2012; DAILY, 1997). Neste contexto, a valoração econômica dos recursos naturais, sendo um processo que visa precificar baseando-se na economia comercial, ou fora dela, ajuda a melhorar nossa compreensão dos benefícios que os 
ecossistemas proporcionam (KENTER et al., 2015). Podendo subsidiar a gestão dos recursos naturais, assegurando assim, sua proteção (ROMEIRO et al., 2009).

As avaliações monetárias de bens e serviços prestados pela natureza têm destacado os efeitos econômicos positivos da preservação e restauração dos ecossistemas (DÍAZ et al., 2015). Trabalhos desenvolvidos nessa perspectiva tiveram seu grande marco com a publicação de Costanza et al. (1997), onde o valor econômico dos bens e serviços do ecossistema global foi calculado em 1,8 vezes o Produto Interno Bruto (PIB) global. Em 2014, essa estimativa foi atualizada, calculando que de 1997 a 2011 perdemos um valor total de U\$4.3-20.2 trilhões/ano devido à mudança de uso da terra (COSTANZA et al., 2014).

Nesse cenário a importância da economia ambiental tem crescido consideravelmente nos últimos anos, o que demonstra a crescente preocupação mundial com relação à perda da biodiversidade (ROMOLOZANO et al., 2017). Devido à ameaça de esgotamento dos recursos naturais foram desenvolvidos várias metodologias que visam levantar o valor intrínseco do bens e serviços ambientais, expressas por meio dos processos de valoração econômica (NASCIMENTO et al., 2013).

No que diz respeito aos métodos de valoração econômica, alguns trabalhos têm sido desenvolvidos no Brasil utilizando o Método de Valoração de Contingente (MVC), para estimar o valor monetário dos ativos ambientais e SE's em UC's. Cirino et al. (2008) aplicaram este médodo revelando a importância e riqueza dos ecossistemas da Área de Proteção Ambiental (APA) São José, em Minas Gerais; Oliveira Júnior et al. (2012) estimaram o valor dos SE's fornecidos pelo Parque Estadual de Itacolomi, Minas Gerais; Reis et al. (2018) identificaram o valor de uso do Parque da Jaqueira na cidade de Recife e Nascimento et al. (2013) estimaram o valor de uso recreacional do Parque Estadual Mãe Bonifácia (PEMB), em Cuiabá, Mato Grosso. Os resultados desses trabalhos revelaram a aplicabilidade do método, bem como destacaram a importância dos serviços ambientais prestados pela natureza.

Estudos como os de Silveira et al. (2013) e Almeida et al. (2017) aliaram à valoração econômica a percepção ambiental e a socioeconomia, e seus resultados revelaram que ambas as variáveis apresentaram relações que explicaram, por exemplo, a elevada ou baixa disposição a pagar dos entrevistados para preservação dos recursos naturais. Neste sentido, destaca-se que tais variáveis devem ser consideradas nos estudos de valoração, dado sua contribuição para compreensão dos fatores que podem afetar a valoração.

Devido à forte relação de dependência dos usuários da Resex-Mar Soure com os recursos vegetais e com base na ótica de Nascimento et al. (2013), onde ressaltam que a valoração econômica desses recursos pode subsidiar decisões do poder público e da sociedade civil para sua gestão, este trabalho objetivou valorar economicamente as plantas úteis nas três comunidades pertencentes a Resex-Mar Soure.

\section{METODOLOGIA}

\section{Área de estudo}

A Reserva Extrativista Marinha de Soure (RESEX-Mar Soure), situada nas coordenadas 0 40' 29,2" S; 40 $30^{\prime}$ 29,7" W, está inserida no arquipélago do Marajó e possui uma extensão territorial de 27.463,58 ha. 
Abriga ecossistemas de restingas, várzeas, manguezais, campos, terra firme e as formações chamadas de tesos (BRASIL, 2001; MMA, 2008; LISBOA, 2012).

Nos limites da Resex-Mar Soure (figura 1) estabeleceram-se três comunidades, à saber: Vila de Pesqueiro (S00 $39^{\prime} 42,2^{\prime \prime}$; W048 $\left.29^{\prime} 08,7^{\prime \prime}\right)$, distante $7 \mathrm{Km}$ do centro urbano da cidade de Soure; Comunidade do Caju-Úna (S00³7'56,1"; W048²9'10,1") distante 18 km; e Povoado do Céu (S00³7'57,1"; W048 $29^{\prime} 10,0^{\prime \prime}$ ) distante a $23 \mathrm{~km}$, sendo muito próxima da Comunidade do Caju-Úna (OLIVEIRA JUNIOR et al., 2012).
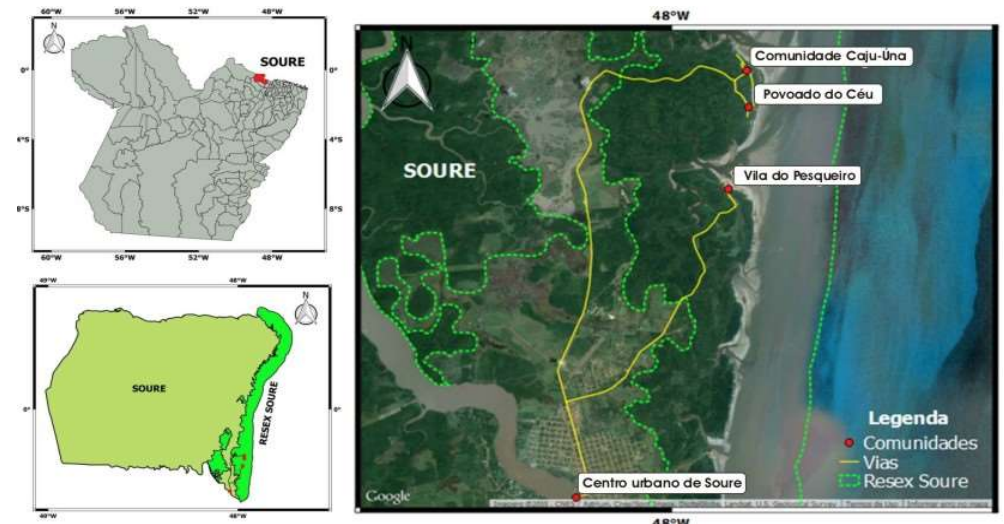

Figura 1: Localização das comunidades tradicionais pertencentes à Reserva Extrativista Marinha de Soure, Pará.

\section{Caracterização Socioeconômica}

No que diz respeito a economia, as três comunidades compartilham das mesmas fontes de renda, envolvendo principalmente os recursos pesqueiros (peixe, camarão e caranguejo); o extrativismo vegetal; agricultura; os benefícios sociais como: Seguro Defeso, Bolsa Verde e Bolsa Família; as aposentadorias e salários de funcionários públicos, sendo que para a Vila do Pesqueiro inclui-se ainda o capital proveniente das atividades turísticas e do artesanato (OLIVEIRA JUNIOR et al., 2012; PINHEIRO et al., 2014).

As moradias, em sua maioria, são construídas em madeira e foram financiadas por projetos federais em parceria com o Instituto Nacional de Colonização e Reforma Agrária (INCRA) (OLIVEIRA JUNIOR et al., 2012). Possuem fornecimento regular de energia elétrica e abastecimento de água encanada, no caso da Vila do Pesqueiro, ou por poços comunitários e caminhões pipas, duas vezes por semana na Comunidade do CajuÚna e Povoado do Céu (LOBATO et al., 2014).

Cada comunidade possui um centro comunitário que geralmente serve aos eventos religiosos, culturais e para as reuniões das associações, escola pública de ensino fundamental e posto de saúde.

Quanto à assistência médica, os tratamentos são acompanhados por agentes de saúde e enfermeiros, e são comumente voltados a enfermidades corriqueiras como viroses, diarreias, dores de cabeça, problemas estomacais e ferimentos, sendo que os casos mais graves são encaminhados ao município de Soure ou então a cidade de Belém (ROCHA et al., 2017).

\section{Delineamento amostral e coleta dos dados}

Considerando o levantamento de Rocha et al. (2017), a população estimada na área da Resex é de aproximadamente 249 famílias, neste sentido foi calculado a amostra com um nível de confiança de $94 \%$, 
conforme a equação a seguir:

$$
n_{o}=\frac{1}{E_{o}^{2}} \text {. }
$$

Onde $E_{o}^{2}$ corresponde ao erro amostral e para este estudo o utilizado foi de $6 \%$. O tamanho da amostra corrigido $n$ foi obtido por meio da equação:

$$
n=\frac{N n_{o}}{N+n_{o}} .
$$

Em que $\mathrm{n}$ corresponde ao tamanho da amostra, $\mathrm{N}$ ao tamanho da população e $\mathrm{n}_{0}$ a primeira aproximação do tamanho da amostra. Neste sentido, para a população $N=249$ famílias, obteve-se o $(n)=131$.

\section{Elaboração dos formulários}

Os formulários foram elaborados com questões abertas e fechadas (ALBUQUERQUE et al., 2016), constituídos de três seções que abordaram: a. socioeconomia; b. percepções sobre o ambiente em que os entrevistados vivem e c. valoração econômica das plantas úteis.

Sobre a socioeconomia foram abordados os seguintes aspectos do entrevistado: a. sexo, b. idade, $\mathbf{c}$. tempo de moradia, d. renda anual, e. número de pessoas no lar, f. tempo de escolaridade.

As questões de percepção ambiental foram elaboradas considerando os seguintes elementos de análise: a. mudanças climáticas, b. poluição ambiental, c. alteração da qualidade de vida das pessoas, d. perda de recursos naturais. Estes elementos foram estruturados na escala de Likert de 5 pontos, em que 0 respondente indica seu grau de concordância ou discordância em relação a determinado objeto (BERMUDES et al. 2016).

Neste estudo, a significação da escala enfocou a frequência com que os entrevistados percebiam a ocorrência dos elementos de análise, onde as pontuações 2, 4, 6, 8 e 10 significam: Sem frequência, Baixa frequência, Indiferente, Frequência e Muita frequência, respectivamente.

Para valorar economicamente as plantas úteis, foi adotado o Método de Valoração de Contingente (MVC), o qual é utilizado para se estimar valores econômicos de todos os tipos de serviços ecossistêmicos (JALA et al., 2015). Este fornece uma preferência declarada pelo entrevistado quanto a seu valor percebido de um recurso e/ou a mudança no valor em função de um cenário específico (BLIGNAUT et al., 2016).

Os valores foram captados por meio da Disposição a Receber (DAR) e Disposição a Pagar (DAP). A forma de eliciação utilizada foi 'aberta ou lances livres', que segundo Motta (1997) ocorre quando o formulário apresenta a seguinte questão: 'quanto você está disposto a pagar e/ou a receber?'. Neste sentido, para captar as preferências declaradas dos entrevistados, foi criado um cenário hipotético de perda dos recursos vegetais, dada a seguinte situação: 'Imagine que a região costeira do município de Soure onde estão localizadas a comunidade do Caju-Úna, o povoado do Céu e a vila do Pesqueiro seja atingida por uma inundação em decorrência do fenômeno da entrada de marés, e como consequência causasse a perda total das espécies vegetais presentes nos quintais dos moradores e entorno das comunidades'. 1. Levando em consideração que você se beneficia desses recursos vegetais, como, por exemplo, o uso de plantas medicinais no trato de doenças, o uso de algumas espécies destinadas a construção, além de serem amplamente 
utilizadas na alimentação, quanto você acredita que deveria receber mensalmente em reais para compensar sua perda?. 2. Caso você não se imagine viver com essa perda, devido à sua forte relação de dependência com esses recursos, quanto você estaria disposto a pagar mensalmente para um fundo de restauração que garantisse restaurar a área devastada?

Antes da entrevista para coleta dos dados, os formulários foram testados com dois comunitários ativos para se verificar a qualidade, clareza e adequação das perguntas ao objetivo do estudo.

\section{Entrevistas}

A coleta de dados seu deu através de entrevistas estruturadas que ocorreram de forma dialogada no período de fevereiro a março de 2018, perfazendo-se duas excursões de quinze dias cada uma. Na primeira foram entrevistados 58 moradores na Vila de Pesqueiro, e na segunda 73, sendo 40 na Comunidade do CajuÚna e 33 no Povoado do Céu, totalizando 131 entrevistados.

\section{Tratamento dos dados e aplicação dos testes estatísticos}

Posteriormente à aplicação dos formulários, os dados foram tabulados usando o software Microsoft Office Excel 2016. Para quantificar a percepção ambiental foi elaborada uma classificação fundamentada em Audino (2017), com adaptações, na qual o grau de percepção variou nos scores de 2 (falta de percepção ecológica) a 10 (alta percepção ecológica).

Após a coleta das preferências declaradas pelos entrevistados o valor econômico total das plantas úteis foi estimado, multiplicando-se as médias de DAR e DAP pelo número total de moradores da Resex-Mar.

As análises estatísticas foram realizadas no programa PAST version 3.18 (HAMMER et al., 2001). Para testar a relação da DAR e DAP com as variáveis socioeconômicas (idade, tempo de moradia, número de pessoas no lares, renda anual e escolaridade) e a percepção ambiental aplicou-se o teste de correlação de Spearman $\left(r_{s}\right)(Z A R, 2009)$.

As diferenças de DAR e DAP entre homens e mulheres foram testadas por meio do teste t. Os valores de DAR e DAP das diferentes comunidades foram comparados usando a análise de variância ANOVA. Quando os pressupostos da análise não foram atingidos foram utilizados testes equivalentes não paramétricos (Kruskal wallis e Mann Whitney) (ZAR, 2009).

\section{RESULTADOS E DISCUSSÃO}

\section{Nível de percepção ambiental entre os comunitários}

A percepção dos moradores das diferentes comunidades sobre os elementos selecionados para tal, revelou-se alto, sendo que a Vila de Pesqueiro obteve o maior score $(9,29)$, seguida do Povoado do Céu $(9,28)$ e Comunidade do Caju-Úna $(9,08)$, respectivamente. Diante disso, verifica-se que questões como perda dos recursos naturais, mudanças climáticas, poluição ambiental e alteração da qualidade de vida fazem parte do conjunto de conhecimentos, sentimentos e pensamentos que caracterizam as percepções ambientais que 
podem estar norteando o comportamento dos moradores.

Lobato et al. (2014) relataram a pesca e a catação do caranguejo fora do período do defeso (perda dos recursos naturais), a extração ilegal de areia (perda dos recursos naturais), despejo de resíduos sólidos na praia (poluição ambiental) e a possíveis alterações na qualidade da água para o consumo humano (alteração na qualidade de vida) como as principais ameaças ambientais. Neste sentido, considera-se que a alta percepção dos moradores acerca das questões investigadas para análise, deva-se à existência dessas ameaças ambientais, as quais compuseram as categorias de análise usadas nesse trabalho, e que foram altamente perceptíveis pelos entrevistados.

Acredita-se que as mobilizações sociais, que ocorreram em função da criação da Resex-Mar Soure, possam ter contribuído com o desenvolvimento de tais percepções ao longo do tempo, assim como a influência do conhecimento tradicional gerado das relações das pessoas com a natureza, os quais foram repassados ao longo das gerações. A esse respeito, Nascimento et al. (2014) ressaltam que as percepções ambientas vem carregadas de simbologias que traduzem a historicidade biológica, cultural e social, são códigos que emergem da vivencia e experiência cotidiana.

Acerca do movimento social que impulsionou a criação dessa UC, Cardoso (2014) relata que esse processo foi fruto da luta da Associação dos Caranguejeiros de Soure (ACS) com o apoio do Centro Nacional de Desenvolvimento das Populações Tradicionais (CNPT) e do Movimento dos Pescadores do Pará (MOPEPA) no combate à exploração predatória dos recursos pesqueiros. Dentro desse contexto, percebe-se que os próprios comunitários se sensibilizaram quando notaram a existência de ameaças ambientais, o que demostra que eles já possuíam percepções a respeito da importância e conservação dos recursos naturais.

Embora as comunidades ainda sofram com ameaças ambientais, os principais problemas que podem comprometer a manutenção do fluxo de serviços ecossistêmicos de provisão, são ocasionadas principalmente pelas ações de pessoas que não residem nas comunidades, como por exemplo, a presença de lixo na praia. A esse respeito a moradora do Povoado do Céu, A. G., 46 anos relatou: 'O lixo que encosta na beira da praia é trazido pela maré de outros lugares, a gente encontra embalagens em outros idiomas'.

A catação do caranguejo fora do período do defeso, outro problema que se constitui como uma ameaça à biodiversidade local também é realizado por pessoas que não residem na Resex-Mar Soure, conforme relatos da moradora da Comunidade do Caju-Úna, V. S., 43 anos: 'As pessoas não respeitam o defeso, pois nessa época se vê os catadores retirando normalmente os caranguejos para comercializarem'.

Diante desses relatos, bem como do elevado nível de percepção encontrado nessa pesquisa, tornase claro que os moradores das três comunidades possuem um elevado conhecimento sobre a dinâmica e funcionamento dos ecossistemas locais, bem como dos principais fatores que ameaçam a biodiversidade local. Embora as ameaças ambientais sejam recorrentes na Resex-Mar Soure, verifica-se que elas são ocasionadas por agentes externos. Dentro desse contexto a população local assume um papel fundamental, no que diz respeito a fiscalização e denúncia ao órgão ambiental competente acerca desses atos ilícitos. 


\section{Estimativas da DAR e DAP}

A maioria dos respondentes estiveram dispostos a contribuir com a valoração das plantas úteis na Resex-Mar Soure, onde 120 (91,60\%) entrevistados estiveram dispostos a receber (DAR) um valor monetário para compensar uma perda ambiental, e 117 (89,31\%) apresentaram disposição a pagar (DAP) para contribuir com um fundo de restauração hipotético, em casos de perda total desses recursos.

Os 11 (8,40\%) entrevistados que não aceitariam nenhum valor no caso de perda das plantas úteis, alegaram que o valor que seria pago aos usuários deveria ser usado em um projeto de recuperação da área devastada. Para esses comunitários nenhum valor pode compensar a perda desses recursos ou substituí-los, diante disso verifica-se que a relação dessas pessoas com as plantas vai além do valor monetário, uma vez que esses recursos fazem parte da caracterização cultural, além de algumas espécies comporem o grupo de plantas místicas, onde seu valor não pode ser mensurado economicamente, pelo fato de seus benefícios serem intangíveis.

Os $14(10,69 \%)$ entrevistados que não estariam dispostos a contribuir com um fundo de restauração hipotético, declararam que isso é papel do governo, uma vez que já pagam impostos, e a única forma pela qual poderiam contribuir com a recuperação da área devastada seria com sua mão de obra. Tais alegações podem ser consideradas como um voto de protesto, no qual as pessoas acreditam ser dever do governo ou de outras organizações pagar pelos serviços ecossistêmicos e bens ambientais, ou então, quando não confiam na organização que administrará o fundo de restauração (TAO et al., 2012; COSTA et al., 2015). O posicionamento desses moradores pode ser um fator negativo, pois acaba impedindo o estabelecimento de uma gestão compartilhada, onde a população interessada fica de fora da tomada de decisão sobre o gerenciamento dos recursos naturais, que influencia diretamente a qualidade de vida da atual sociedade e das futuras gerações (ARAÚJO et al., 2015).

Ao analisar os valores estimados na tabela 1, verifica-se que a DAR é expressivamente maior que a DAP, isso revela que a preferência dos entrevistados, no caso hipotético de perda das plantas úteis é receber uma compensação monetária. A esse respeito Blignaut et al. (2016) ressaltam que evidências empíricas indicam que as estimativas de DAP são consideravelmente menores do que as de DAR.

Tabela 1: Estimativa do valor total das plantas úteis.

\begin{tabular}{|c|c|c|c|c|}
\hline & \multicolumn{2}{|c|}{ Disposição a Receber (DAR) } & \multicolumn{2}{|c|}{ Disposição a Pagar (DAP) } \\
\hline & Média Mensal & Média Anual & Média Mensal & Média Anual \\
\hline $\mathrm{R} \$$ & $302.350,74$ & $3.628 .208,88$ & $43.301,10$ & $519.613,20$ \\
\hline
\end{tabular}

Os resultados obtidos nesse trabalho assemelham-se aos de Huang et al. (2013), cuja DAP dos entrevistados para uma melhoria hipotética na qualidade da água do lago Hongze na china, foi menor que sua DAR se certas melhorias não fossem realizadas. No trabalho de Blingnaut et al. (2016) ao estimarem o valor de amenidade dos recursos costeiro de Abu Dhabi em Dubai, também constataram que o valor DAR foi menor que a DAP. Observa-se que tanto neste estudo, quanto nos trabalhos supracitados que a preferência revelada dos entrevistados está em receber uma compensação.

Ressalta-se que o valor de $\mathrm{R} \$ 3.628 .208,88$ como DAR refere-se apenas às plantas úteis presentes na 
Resex-Mar Soure, entretanto nos estudos de Nascimento et al. (2013) e Araújo et al. (2015) que valoraram Unidades de Conservação incluindo todos os SE's prestados pelo ambiente, os valores foram de $\mathrm{R} \$ 812.490,00$ e $\mathrm{R} \$ 1.280 .885,33$, respectivamente. Diante disso, observa-se que o elevado valor de DAR estimado na Resex-Mar Soure demonstra a forte ligação dessas populações com as plantas, que vai desde aspectos de subsistência, passando pelos espirituais até os culturais, como relatado por Rocha et al. (2017).

\section{Fatores que afetam a DAR}

A média da DAR dos moradores na Resex-Mar Soure é de $\mathrm{R} \$ 1.214,26$ com um intervalo de confiança de $95 \%$ com limite inferior de $\mathrm{R} \$ 1.133,36$ e limite superior de $\mathrm{R} \$ 1.294,76$. O Valor mínimo individual foi de R\$0 e máximo R\$5.000, tendo um desvio padrão 92,43.

O alto valor médio de DAR deve-se aos elevados lances de preferência declarada pelos entrevistados, dentre os quais os mais citados foram $\mathrm{R} \$ 954,00$ e $\mathrm{R} \$ 1.908,00$ (um e dois salários mínimo, respectivamente). Diante disso, percebeu-se que grande parte dos informantes assumiram como base de valor o salário mínimo, o que pode ser justificado pelo fato destes serem beneficiados por programas assistencialistas do governo federal, como o seguro defeso, cujo pagamento dá-se anualmente em quatro parcelas de $\mathrm{R} \$ 954,00$ cada, além das aposentadorias e salários de funcionários públicos pagos no valor de R\$954,00.

Analisando a tabela 2, nota-se que existe uma diferença significativa do valor relativo da DAR entre os moradores das três comunidades $(H=5.32 p=0.03)$, sendo que os valores informados pelos moradores do Pesqueiro diferem estatisticamente dos revelados pelos do Povoado do Céu. Em outras palavras, os moradores desta última apresentam uma menor DAR por uma compensação. Entretanto, os entrevistados no Caju-Úna apresentaram valores semelhantes aos do Pesqueiro e Céu.

Tabela 2: Análise de variância da DAR entre as três comunidades.

\begin{tabular}{llll}
\hline & \multicolumn{1}{c}{ Pesqueiro } & Caju-Úna & Céu \\
\cline { 2 - 4 } $\begin{array}{l}\text { Pesqueiro } \\
\text { Caju-Úna }\end{array}$ & 0.1022 & 0.1022 & $0.009087^{*}$ \\
Céu & $0.009087^{*}$ & & 0.6925 \\
\hline
\end{tabular}

Nota: *diferem significativamente.

Acredita-se que a maior DAR na Vila de Pesqueiro ocorreu devido a esta comunidade ser a mais beneficiada com o turismo, o que pode ter gerando nos moradores maior noção de valor, haja vista que muitos deles complementam sua renda com práticas oriundas dessa atividade, como por exemplo passeio de búfalo na praia; oferta de atrativos gastronômicos locais: peixes, camarão e caranguejo; venda de artesanato; além da comercialização de produtos provenientes da medicina tradicional como: óleo de andiroba (Carapa guianensis Aubl.), de bicho do tucumã (Astrocaryum vulgare Mart.) e de coco (Cocos nucifera L.).

Ao se aplicar a análise de variância para verificar se existia diferença da DAR entre os gêneros, o resultado do teste $(U=1879 p=0.20)$ revelou que embora a DAR seja maior para homens, o mesmo não apresentou diferença estatisticamente significativa. Ao se relacionar as variáveis socioeconômicas com a DAR, observou-se que estas não afetam a disposição dos moradores para receber uma compensação, em 
casos de perda total das plantas úteis (tabela 3).

Tabela 3: Correlação das variáveis socioeconômicas com a DAR e a DAP

\begin{tabular}{lllll} 
& \multicolumn{1}{l}{ DAR } & DAP & \\
\cline { 2 - 5 } & Valor de $\mathbf{r}_{\mathbf{s}}$ & Valor de $\mathbf{p}$ & Valor de $\mathbf{r}_{\mathbf{s}}$ & Valor de $\mathbf{p}$ \\
\hline Idade & -0.13 & 0.12 & -0.18 & $0.03^{*}$ \\
Tempo de moradia & -0.02 & 0.74 & -0.03 & 0.70 \\
Renda anual & 0.02 & 0.78 & -0.09 & 0.26 \\
Número de pessoas no lar & -0.13 & 0.13 & -0.01 & 0.85 \\
Tempo de escolaridade & 0.12 & 0.15 & 0.04 & 0.63 \\
\hline
\end{tabular}

Nota: apresenta relação estatisticamente significativa.

A correlação de Spearman, não evidenciou uma relação direta entre DAR e percepção ambiental $\left(r_{s}=-\right.$ $0.09 p=0.29$ ), sugerindo que, apesar de elevada, a percepção não possui relação estatisticamente significativa com a DAR. Esses resultados contrastam com os encontrados por Silveira et al. (2013) e Almeida et al. (2017), que ao utilizaram a valoração de contingência para estimar o valor de ativos ambientais em Unidades de Conservação, as variáveis socioeconômicas como: renda familiar e idade, bem como o nível de percepção ambiental se correlacionaram com a valoração.

Levando em consideração que grande parte dos entrevistados adotaram como base de valor o salário mínimo para dar os lances de DAR, bem como o elevado nível de percepção ambiental presente entre os entrevistados das três comunidades, a matriz de dados gerada nesse trabalho foi homogênea (sem variação), por este motivo não foi possível visualizar prováveis correlações dos fatores socioeconômicos e da percepção ambiental com a valoração, entretanto não significa dizer que não exista relação entre essas variáveis, apenas que a partir da matriz de dados sem variação isso não foi possível.

\section{Fatores que afetam a DAP}

O valor médio mensal da DAP pelos moradores é de $\mathrm{R} \$ 173,67$ com um intervalo de confiança de $95 \%$ com limite inferior de $\mathrm{R} \$ 132.19$ e limite superior de $\mathrm{R} \$ 210.80$. O valor mínimo individual foi de $\mathrm{R} \$ 0$ e máximo de $R \$ 1000$, tendo um desvio padrão de 230,14. A média mensal encontrada nesse trabalho é superior as encontradas por Nascimento et al. (2013), Oliveira Júnior et al. (2012) e Camargo et al. (2017), que estimaram a DAP mensal dos usuários em Unidades de Conservação, obtendo os valores médio de $R \$ 1,00, R \$ 4,26$ e $\mathrm{R} \$ 9,75$ respectivamente.

Diante do exposto, fica claro que os moradores apresentam uma média superior as encontradas por outros autores na literatura, acredita-se que esse resultado seja fruto da preocupação dos comunitários em preservar os recursos vegetais, bem como da forte relação de dependência das populações tradicionais com os recursos da natureza. A esse respeito, Lobato et al. (2014) ressaltaram que o modo de vida e a cultura dos usuários da Resex-Mar Soure é caracterizada pela sua intensa relação com a natureza.

De acordo com o resultado indicado na figura 2, não há diferença significativa do valor relativo a DAP entre os moradores das três comunidades $(\mathrm{F}=0.54 \mathrm{p}=0.58)$, e embora a disposição a receber seja maior nos homens, não há diferença significativa entre gêneros $(U=1920 p=0.19)$. 


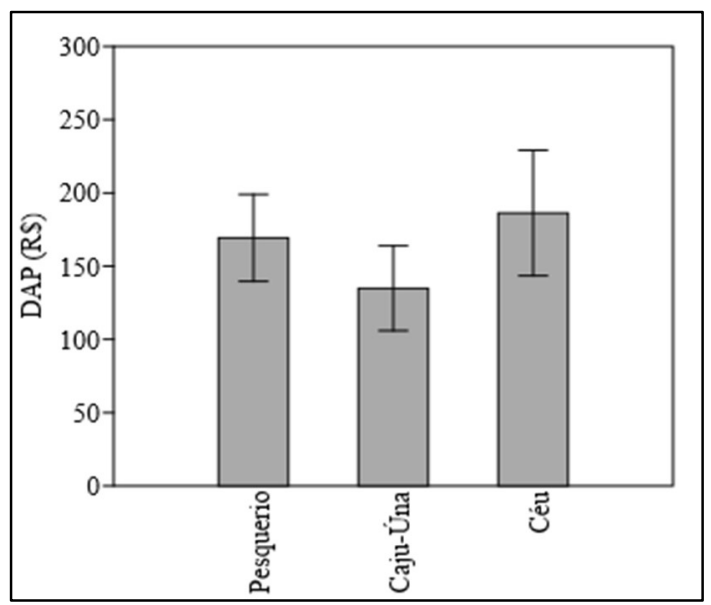

Figura 2: Análise de variância da DAP entre as três comunidades.

A correlação de Spearman, não evidenciou relação da DAP com tempo de moradia, renda, número de pessoas no lar e tempo de escolaridade (tabela 3). Entretanto a DAP apresentou relação estatisticamente significativa com a idade (tabela 3), pois verificou-se que os mais velhos estimaram menores valores em relação aos mais jovens. Acredita-se que os entrevistados dessa faixa etária, por estarem culturalmente condicionados a obterem 'gratuitamente' suas provisões pela extração dos recursos naturais ou por benefícios e Programas Sociais, não possuem uma consciência a pagar pelos serviços ambientais. Nesse resultado, evidencia-se, indiretamente um voto de protesto por esses moradores, uma vez que segunda essa classificação é dever do governo pagar pelos serviços ambientais.

A correlação de Spearman, não demonstrou relação direta entre DAP e percepção ambiental $\left(r_{s}=-\right.$ $0.05 \mathrm{p}=0.54)$, sugerindo que, apesar de elevada, a percepção não influencia na DAP. Esses resultados contrastam com os encontrados por Silveira et al. (2013) e Almeida et al. (2017), que ao utilizaram a valoração de contingência para estimar o valor de ativos ambientais em Unidades de Conservação, as variáveis socioeconômicas, bem como o nível de percepção ambiental se correlacionaram com a valoração.

Ressalta-se que a não correlação da DAP com a percepção ambiental e os fatores socioeconômicos, deu-se pelo mesmo motivo da não correlação destes com a DAR, haja vista que a matriz de dados obtida nesse trabalho não apresentou variação.

\section{CONCLUSÕES}

Diante dos resultados, considera-se que o valor estimado pelo processo de valoração econômica é alto, e isso se deu graças à elevada disposição dos entrevistados a receber uma compensação, em caso hipotético de perda, ou a pagar pela preservação das plantas úteis. Isso reflete a preocupação dos moradores pela manutenção dos recursos vegetais na natureza, uma vez que eles dependem do serviço ecossistêmico de provisão proporcionado por esses ativos.

Verificou-se que há uma uniformização do conhecimento nas três comunidades a respeito das questões ambientas e dos lances livres (DAR e DAP), pois embora a amostragem tenha sido obtida em diferentes comunidades, separadas geograficamente e com pessoas de diferentes faixas etária, gênero, renda anual, tempo de moradia, números de pessoas no lar e 100\% deles apresentarem uma alta percepção 
ambiental, nenhuma variável socioeconômica, tampouco o nível de percepção ambiental se correlacionou estatisticamente com a DAR e DAP, exceto a idade com a DAP.

O valor estimado através do processo de valoração econômica neste estudo, pode ser usado como um indicativo para contabilização do capital natural (plantas úteis) na Resex-Mar Soure, além de configurarse como um subsídio em projetos que garantam e reforcem o papel da conservação desses recursos, considerando que essa UC vem sofrendo com ameaças ambientais.

\section{REFERÊNCIAS}

ALBUQUERQUE, U. P.; LUCENA, R. F. P.; CUNHA, L. V. F. C.. Métodos e técnicas na pesquisa etnobiológica e etnoecológica. 3 ed. Recife: NUPPEA, 2016.

ALMEIDA, A. N.; VERSIANI, R. O.; SOARES, P. R. C.; ANGELO, H.. Avaliação Ambiental do Parque Olhos D ' Água: Aplicação do Método da Disposição a Pagar. Floresta e Ambiente, v.24, p.1-11, 2017.

ARAÚJO, H. R.; OLIVEIRA JÚNIOR, A. F.; AZEVEDO, A. A.. Valoração de serviços ambientais: subsídio para a sustentabilidade do atrativo natural Gruta do Salitre, Diamantina, Minas Gerais. Pesquisas em Turismo e Paisagens, v.8, n.1, p.17-26, 2015.

AUDINO, V.. Elaboração de um instrumento sobre a percepção ambiental da população urbana para a sustentabilidade de cidades. Dissertação (Mestrado em Sustentabilidade Socioeconômica e Ambiental) Universidade Federal de Ouro Preto, Ouro Preto, 2017.

BERMUDES, W. L.; SANTANA, B. T.; BRAGA, J. H. O.; SOUZA, P. H.. Tipos de escalas utilizadas em pesquisas e suas aplicações. Revista Vértices, v.18, n.2, p.7-20, 2016.

BLIGNAUT, J.; MANDER, M.; INGLESI-LOTZ, R.; GLAVAN, J.; PARR, S.. The amenity value of Abu Dhabi's coastal and marine resources to its beach visitors. Ecosystem Services, v.19, p.32-41, 2016. DOI:

http://dx.doi.org/10.1016/j.ecoser.2016.04.005

BRASIL. Decreto de 22 de novembro de 2001. Cria a Reserva Extrativista Marinha de Soure, no município de Soure, estado do Pará, e dá outras providências. Brasília: DOU, 2001.

CAMARGO, P. L. T.; OLIVEIRA JÚNIOR, A. F.; LAMIN-GUEDES, V.; TEIXEIRA, M. B.; MARTINS JUNIOR, P. P.. Uso da metodologia de valoração de contingente para o cálculo do valor ambiental do vetor norte do Parque Estadual do Itacolomi (Mariana-MG). Revista Ibero-Americana de Ciências Ambientais, v.8, n.3, 2017.

CARDOSO, M. S. C.. Pescadores da Reserva Extrativista Marinha de Soure: Práticas sociais no território. 2014. Dissertação (Mestrado em Serviço Social) - Universidade Federal do Pará, Belém, 2014.

CIRINO, J. F.; LIMA, J. E.. Valoração contingente da Área de Proteção Ambiental (APA) São José/MG: um estudo de caso. Revista de Economia e Sociologia Rural, v.46, n.3, p.647672, 2008.
COSTA, M. E. L.; SOUZA, R. A. T. M.; RIBEIRO, A. R.; PASA, M. C.. Respostas de protesto na disposição a pagar espontânea e induzida nas técnicas de lances livres e referendo pelo método de valoração contingente. Biodiversidade, v.14, n.1, p.117-144, 2015.

COSTANZA, R.; DARGE, R.; DE GROOT, R.; FARBER, S.; GRASSO, M.; HANNON, B.; LIMBURG, K.; NAEEM, S.; O'NEILL, R. V.; PARUELO, J.; RASKIM, R. G.; SUTTON, P.; BELT, M. V. D.. The Value of the World's Ecosystem Services and Natural Capital The value of the world's ecosystem services and natural capital. Nature, v.387, p.253-260, 1997.

COSTANZA, R.; GROOT, R.; SUTTON, P.; VAN DER PLOEG, S.; ANDERSON, S. J.; KUBISZEWSKI, I.; FARBER, S.; TURNER, R. K.. Changes in the global value of ecosystem services. Global Environmental Change, v.26, p.152-158, 2014. DOI: http://dx.doi.org/10.1016/j.gloenvcha.2014.04.002

CRESPIN, S. J.; SIMONETTI, J. A.. Loss of ecosystem services and the decapitalization of nature in El Salvador. Ecosystem Services, v.17, p.5-13, 2016. DOI:

http://dx.doi.org/10.1016/j.ecoser.2015.10.020

DAILY, G. C.. Nature's services: societal dependence on natural systems. Washington: Island Press, 1997.

DALY, H.. A note in defense of the concept of natural capital. Ecosyst.em Services, v.41, p.1-3, 2020. DOI: https://doi.org/10.1016/j.ecoser.2019.101051

DÍAZ, S.; DEMISSEW, S.; CARABIAS, J.; JOLY, C.; LONSDALE, M.; ASH, N.; LARIGAUDERIE, A.; ADHIKARI, J. R.; ARICO, S.; BÁLDI, A.; BARTUSKA, A.; BASTE, I. A.; BILGIN, A.; BRONDIZIO, E.; CHAN, K. M. A.. The IPBES Conceptual Framework: connecting nature and people. Current Opinion in Environmental Sustainability, v.14, p.1-16, 2015. DOI: http://dx.doi.org/10.1016/j.cosust.2014.11.002

GROOT, R.; BRANDER, L.; PLOEG, S. V. D.; COSTANZA, R.; BERNARD, F.; BRAAT, L.; CHRISTIE, M.; CROSSMAN, N.; GHERMANDI, A.; HEIN, L.; HUSSAIN, S.; KUMAR, P.; MCVITTIE, A.; PORTELA, R.; RODRIGUEZ, L. C.; BEUKERING, P. V.. Global estimates of the value of ecosystems and their services in monetary units. Ecosystem Services, v.1, n.1, p.50-61, 2012. DOI: http://dx.doi.org/10.1016/j.ecoser.2012.07.005

HAMMER, Ø.; HARPER, D. A. T.; RYAN, P. D.. Past: Paleontological Statistics Software Package for Education and Data Analysis. Paleontologia Electronica, v.4, n.1, 2001.

JALA; NANDAGIRI, L.. Evaluation of Economic Value of 
Pilikula Lake using Travel Cost and Contingent Valuation Methods. Aquatic Procedia, v.4, p.1315-1321, 2015. DOI: https://doi.org/10.1016/i.aqpro.2015.02.171

KENTER, J. O.; O'BRIEN, L.; HOCKLEY, N.; RAVENSCROFT, N.; FAZEY, I.; IRVINE, K. N.; REED, M. S.; CHRISTIE, M.; BRADY, E.; BRYCE, R.; CHURCH, A.; COOPER, N.; DAVIES, A.; EVELY, A.; EVERARD, M.; FISH, R.; FISHER, J. A.; JOBSTVOGT, N.; MOLLOY, C.; ORCHARD-WE, S.. What are shared and social values of ecosystems? Ecological Economics, v.111, p.86-99, 2015. DOI:

http://dx.doi.org/10.1016/j.ecolecon.2015.01.006

KVALVIK, I.; SOLÅS, A.; SØRDAHL, P. B.. Introducing the ecosystem services concept in Norwegian coastal zone planning. Ecosystem Services, v.42, p.1-11, 2020. DOI: https://doi.org/10.1016/j.ecoser.2020.101071

LISBOA, P. L. B.. A terra dos Aruã: uma história ecológica do arquipélago do Marajó. Belém: Museu Paraense Emílio Goeldi, 2012.

LOBATO, G. J. M.; TAVARES-MARTINS, A. C. C.; LUCAS, F. C. A.; MORALES, G. P. M.; ROCHA, T. T.. Reserva Extrativista Marinha de Soure, Pará, Brasil: modo de vida das comunidades e ameaças ambientais. Biota Amazônia, v.4, n.4, p.66-74, 2014.

MMA. Ministério do Meio Ambiente. Termo de Referência para Apoio na Elaboração do Plano de Manejo Participativo: Fase 1 da Reserva Extrativista Marinha de Soure. Brasília: MMA, 2008.

NASCIMENTO, S. T. M. F.; RIBEIRO, E. S.; SOUSA, R. A. T. M.. Valoração econômica de uma unidade de conservação urbana, Cuiabá, Mato Grosso. Interações, v.14, n.1, p.79-88, 2013.

OLIVEIRA JÚNIOR, A. F.; COSTA, T. P. P.; TAFURI, A. C.. Valoração contingente dos serviços ecossistêmicos providos pelo Parque Estadual do Itacolomi, MG. Informe Agropecuário, v.33, n.271, p.108-115, 2012.

PINHEIRO, L. B. C.; LIMA, F. S.; ROCHA, T. T.; TAVARESMARTINS, A. C. C.. Educação Ambiental e Participação Social: Sustentabilidade na Reserva Extrativista Marinha de Soure, Ilha Do Marajó, Pará, Brasil. Educação Ambiental em Ação, v.46, n.3, 2014.

REIS, J. V.; SILVA, J. F.. Valoração ambiental do Parque da Jaqueira (Recife, Pernambuco-Brasil). Revista Nacional de Gerenciamento de Cidades, v.6, n.37, p.103-119, 2018.
ROCHA, T. T.; TAVARES-MARTINS, A. C. C.; LUCAS, F. C. A.. Traditional populations in environmentally protected areas: an ethnobotanical study in the Soure Marine Extractive Reserve of Brazil. Boletín Latinoamericano y del Caribe de Plantas Medicinales y Aromáticas, v.16, n.4, p.410-427, 2017.

ROMEIRO, A. R.; ANDRADE, D. C.. Valoração econômicoecológica de recursos naturais. Revista Gestión y Ambiente, v.12, n.3, p.21-36, 2009.

ROMO-LOZANO, J. L; LÓPEZ-UPTON, J.; VARGASHERNÁNDEZ, J. J; ÁVILA-ANGULO, M. L.. Economic valuation of the forest biodiversity in Mexico, a review. Revista Chapingo Serie Ciencias Forestales y del Ambiente, v.23, n.1, p.75-90, 2017. DOI: http://dx.doi.org/10.5154/r.rchscfa.2016.03.015

SILVA, A. T. R.. A conservação da biodiversidade entre os saberes da tradição e a ciência. Estudos Avançados, v.29, n.83, p.233-260, 2015.

SILVEIRA, V. C.; CIRINO, J. F.; PRADO FILHO, J. F.. Valoração econômica da área de proteção ambiental estadual da Cachoeira das Andorinhas/MG. Revista Árvore, v.37, n.2, p.257-266, 2013.

SMITH, A. C.; HARRISON, P. A.; PÉREZ SOBA, M.; ARCHAUX, F.; BLICHARSKA, M.; EGOH, B. N.; ERŐS, T.; FABREGA DOMENECH, N.; GYÖRGY, I.; HAINES-YOUNG, R.; LI, S.; LOMMELEN, E.; MEIRESONNE, L.; MIGUEL AYALA, L.; MONONEN, L.; SIMPSON, G.; STANGE, E.; TURKELBOOM, F.; UITERWIJK, M.; VEERKAMP, C. J.; WYLLIE DE ECHEVERRIA, V.. How natural capital delivers ecosystem services: A typology derived from a systematic review. Ecosystem Services, v.26, p.111-126, 2017. DOI: http://dx.doi.org/10.1016/i.ecoser.2017.06.006

TAO, Z.; YAN, H.; ZHAN, J.. Economic Valuation of Forest Ecosystem Services in Heshui Watershed using Contingent Valuation Method. Procedia Environmental Sciences, v.13, p.2445-2450, 2012.

TEIXEIRA, T. H.; NETO, J. A. F.; MOURA, R. A.; FIGUEIREDO, N. A.. As Unidades de Conservação de uso sustentável no bioma Amazônico: dilemas e perspectivas para o desenvolvimento sustentável. Revista Portuguesa de Estudos Regionais, n.46, p.72-89, 2017.

ZAR, H. J.. Biostatistical analysis. 5 ed. Pearson: New Jersey, 2009.

A CBPC - Companhia Brasileira de Produção Científica (CNPJ: 11.221.422/0001-03) detém os direitos materiais desta publicação. Os direitos referem-se à publicação do trabalho em qualquer parte do mundo incluindo os direitos às renovações, expansões e disseminações da contribuicão, bem como outros direitos subsidiários. Todos os trabalhos publicados eletronicamente poderão posteriormente ser publicados em coletâneas impressas sob coordenação da Sustenere Publishing, da Companhia Brasileira de Produção Científica e seus parceiros autorizados. Os (as) autores (as) posteriormente ser publicados em coletâneas impressas sob coordenação da Sustenere Publishing, da Companhia Brasileira de Produção Cientifica e seus pãc 